\title{
Rescate y difusión del patrimonio cultural de Nandayure y Liberia por medio de la producción de dos largometrajes documentales
}

\author{
Compilation and dissemination of the cultural heritage of Nandayure and Liberia \\ through the production of two documentary feature films
}

\author{
José Pablo Castillo Valverde ${ }^{1}$ \\ Universidad Estatal a Distancia, Costa Rica
}

\begin{abstract}
Resumen: La riqueza histórica-cultural y en recursos naturales de las comunidades de Guanacaste ha convertido a esta provincia en sitio ideal para la producción documental educativa.

El desarrollo de la promoción en redes sociales y dispositivos inteligentes ha hecho que dicho tipo de audiovisual tenga salida en las mismas comunidades. La inversión en promocionar tales producciones por medio de las redes permite que los habitantes de esa región puedan disfrutar de su propia cultura y sus orígenes al ver retratada su cotidianidad e historia en estos mismos audiovisuales.
\end{abstract}

Por una parte, esta inversión debe ser parte de las estrategias de extensión de las universidades estatales que poseen oficinas dedicadas a la producción audiovisual educativa.

Por otra parte, resulta también importante que el documental se convierta en una ventana para que dichas tradiciones sean vistas fuera de Costa Rica. Existen diferentes rutas para ello; pero una muy importante corresponde a las inscripciones y participaciones en concursos y festivales internacionales de cine.

Un acercamiento de dicho tipo de productos y experiencias de trabajo que engloban los elementos mencionados, son los documentales de la UNED, «Las Tierras de la Princesa Nandayure» y «Una Fiesta en Liberia».

Palabras clave: audiovisual, documental, Guanacaste, Liberia, Nandayure

Abstract: The historical and cultural richness along with the diversity in natural resources in Guanacaste, Costa Rica empowers communities of this region to be an ideal place for producing educative documentaries.

Recent developments in social media promotion and in electronic intelligent devices stimulate the inhabitants of that same communities to watch and enjoy this form of audiovisual research. It is necessary to promote these audiovisual productions in social networks for native people of guanacastecan towns in order to appreciate their own culture, origins and history reflected in those documentaries.

Investment in social media promotion strategies should be planned within public universities as part of their extension programs. Financing these strategies should be part of the production logistics in offices dedicated to educative audiovisual production.

It is also important for documentaries to become exterior windows for traditions that have been filmed and watched in other countries outside Costa Rica. There are different routes to make it possible, but a very important one is the inscription of these documentaries in international film festivals and also to participate on international movie competitions.

Two examples of these documentary products are «The Lands of Princess Nandayure» and «A Festival in Liberia»; both produced by the Audiovisual Production Center of the State University of Distance Learning in Costa Rica.

Keywords: audiovisual, documentary, Guanacaste, Liberia, Nandayure

\footnotetext{
${ }^{1}$ Máster en Tecnología Educativa. Es productor audiovisual del Programa de Producción de Material Audiovisual de la Universidad Estatal a Distancia, Costa Rica. Dirección electrónica: jpcastillov@uned.ac.cr, josepablocastillov@gmail.com
} 


\section{Introducción}

El reflejo de la vida cotidiana, la historia y las representaciones culturales que aún se conservan en algunas comunidades de Guanacaste permiten que tales sitios tengan un tremendo potencial para la documentación audiovisual de esas realidades. Lo anterior mediante la implementación de las nuevas tecnologías de corte profesional para registro sonoro y de imagen en alta definición.

En este tema, cabe acotar también la incorporación del reflejo de esas realidades de los pueblos mediante la organización de un relato audiovisual que incorpore una narrativa y una estructura dramática atractiva. Así, se generan productos llamativos que muestren su historia y cultura a las nuevas generaciones que habitan estos mismos lugares. Con respecto al tema, Petrozzi (2018) argumenta que "la obra audiovisual se ha convertido en los últimos tiempos en un instrumento no solamente para narrar historias, para generar entretenimiento, generar ilusiones, sino también como herramienta de promoción de la riqueza cultural de nuestros pueblos" (p. 145).

Esto convierte al documental, como uno de los dos grandes géneros de la cinematografía, en un medio educativo primordial para la muestra de estas representaciones culturales en las comunidades. Sobre este mismo análisis, Getino (2007) profundiza

Podría afirmarse que los espectadores y los públicos deben ser estudiados en los contextos culturales e históricos que explican su existencia, y que el texto o el discurso audiovisual nunca posee un significado unívoco impuesto por el productor del mensaje, sino que el mismo se redefine -por reproducción, adaptación, o negación- desde la ubicación social de cada persona o de cada segmento de público, con sus predisposiciones, prejuicios y resistencias elaboradas de antemano en el marco de su particular $y$ diferenciada situación ( $p$. 181).

En este contexto, diversos sitios de la provincia de Guanacaste, en Costa Rica se caracterizan por un potencial para el registro audiovisual y la estructuración de relatos complejos. Se trata de documentales que promuevan el rescate de la cultura gracias al registro de la variedad de tradiciones, historia, cultura y arquitectura de esos pueblos y ciudades que se distribuyen por una provincia considerada como cuna del folclore costarricense. Se trata de elementos, que sumados a la belleza fotográfica de los escenarios naturales que rodean a estos centros de población, brindan un potencial extra para que tanto productoras estatales como privadas enmarquen trabajos audiovisuales a lo largo y ancho de la provincia.

\section{Domínguez (2005) afirma que}

al hacer un documental estamos creando una herramienta de investigación en la que se presenta una situación o evento actual desde la perspectiva del director, y que en futuras generaciones puede usarse como un documento para informarnos de eventos pasados (p. 54).

Por este motivo, resulta convincente la importancia de la preservación de estos elementos culturales por medio del registro documental en las comunidades guanacastecas. Igualmente, se debe agregar que ese tipo de productos presentan un potencial para ser distribuidos en dos vías. Primero dentro de la provincia, en donde los mismos habitantes podrían estar interesados en ver retratada su cultura y verse reflejados ellos 
mismos. Y, segundo, la exhibición fuera de los límites provinciales y aún más allá de las fronteras de Costa Rica.

El impulso de la Universidad Estatal a Distancia (UNED) en la generación de productos audiovisuales que muestren la cotidianidad y el patrimonio cultural de los pueblos forma parte de los vínculos que emana desde la actividad universitaria hacia las comunidades. Así pues, como parte de ese trabajo de extensión, se encuentra la vinculación mediante el trabajo de producción documental.

La proyección universitaria más allá de las aulas involucra a la UNED en las realidades de los pueblos; en este caso particular, los pueblos guanacastecos, sabidos de una enorme riqueza de patrimonio cultural y folclore. Por ende, la documentación audiovisual de las realidades de esas comunidades ha sido un pilar en los objetivos extensionistas de diversos proyectos universitarios.

Los trabajos documentales de la UNED en todo el país, pero en particular en la región guanacasteca, han permitido, durante años, difundir y preservar las diversas identidades de los pueblos. La UNED se ha caracterizado por retratar en imágenes en movimiento los distintos rasgos característicos de las comunidades. La iniciativa fomenta el resguardo de aspectos importantísimos de la identidad costarricense.

La historia de la producción documental y de la difusión de productos audiovisuales en la UNED se remonta casi al propio origen de la Universidad, en 1977. La misma ley de creación establece desde su artículo primero que se funda la UNED "como una institución de educación superior especializada en la enseñanza a través de los medios de comunicación social" (Ley n. $\left.{ }^{\circ} 6044,1977\right)$.

Desde entonces, esta casa de estudios adquirió un compromiso en el tema de la comunicación audiovisual con la creación de la entonces Oficina de Audiovisuales, hoy más conocida en la realidad costarricense como Audiovisuales UNED. Desde sus inicios, tal departamento incorporó una serie de formatos de productos audiovisuales educativos entre los que comenzó a destacar el documental, por el papel protagónico que adquirió en las comunidades.

Durante los años 80, dichos productos se difundían a los estudiantes en los medios electrónicos del momento: la radio y la televisión. Con el pasar de los años, los sistemas de distribución fueron cambiando y se incorporaron los reproductores de video en los hogares. Entre estos soportes, se encontraban los más populares de su época; el VHS y los DVD; y, después del 2010, también los Blu-rays.

En el ámbito comercial, en el 2005 apareció YouTube, gracias al desarrollo y mejoramiento de internet, del ancho de banda y de una mayor eficiencia en el trasiego de los productos audiovisuales en línea. Esta plataforma de reproducción de video comenzó a revolucionar los hábitos de consumo de audiovisuales por medio de internet. La UNED no se quiso quedar atrás en este tema y encontró una oportunidad nueva para hacer llegar sus productos educativos a los estudiantes y al público general.

Por eso, desde el 2008, inició la gestación del proyecto de la plataforma de audiovisuales a la carta de la UNED. La ejecución se extendió durante dos años y en el 2010 entró en funcionamiento. La entonces nueva plataforma de audiovisuales a la carta se convirtió en una alternativa novedosa para la educación en línea. En ese momento, esa plataforma llegó a ser para la UNED una especie de YouTube educativo, único en su género.

Transcurrieron los años y avanzó el desarrollo de las plataformas de pago de películas. En aquel momento, los audiovisuales se comenzaron a subir a la 
red en calidad de alta definición. También se desarrolló la reproducción en otros medios más allá de la computadora. Entre estos nuevos medios destacaban los teléfonos y televisores inteligentes, además de las tabletas electrónicas.

En el ámbito comercial internacional, Netflix, Amazon Prime Video y otras plataformas revolucionaron el consumo de cine a la carta. En la Universidad, para el 2014, Audiovisuales UNED comenzó un proceso de cambio de su equipo de grabación analógico a equipos digitales en alta definición; incluso, en algunos productos, hasta la resolución en $4 \mathrm{~K}$. Calidades, pues, más afines ya a la producción cinematográfica digital. De ese modo, la UNED modernizó tecnológicamente su producción audiovisual educativa.

Con estos avances, la primera plataforma de video a la carta de Audiovisuales UNED quedó obsoleta y en el 2016 se incursionó en un canal de YouTube para poner a disposición sus productos. Posteriormente, en el 2019 comenzó el desarrollo de una nueva plataforma propia de distribución de video educativo en línea, basada en el funcionamiento de la plataforma comercial Netflix.

En la UNED, tal evolución ocurre en forma constante desde hace más de 40 años, con el fin de difundir y divulgar más $\mathrm{y}$ mejores productos audiovisuales a disposición de sus propios estudiantes, de estudiantes de otras universidades dentro y fuera del país, y para el público general.

Por lo tanto, es fundamental la difusión de los productos que Audiovisuales UNED realiza gracias a los nuevos medios digitales y también vía presentación en salas de exhibición de cine digital. En este artículo, se abordará el caso de la difusión que se le ha dado a dos largometrajes documentales realizados en importantes centros de población de Guanacaste: Nandayure y Liberia.

\section{Desarrollo del tema}

Según Miller (2017), hay muchas maneras de definir cultura: desde la economía, desde la política, desde determinada ideología, desde la religión, desde un discurso folclorista y aun ahora desde las corrientes feministas. La cultura se entiende porque establece las diferencias con respecto a otros y las similitudes que hacen parte a los individuos de un mismo contexto. En las sociedades actuales, industrias y prácticas artísticas como el teatro, el cine, la televisión, la radio, la pintura, la confección de artesanías, la escritura, la música, la danza y los juegos de video se enmarcan como prácticas culturales también, así como una cultura es determinada por ciertos elementos como el lenguaje, la religión, intercambios económicos, las costumbres, los tiempos y los espacios comunes.

Este acercamiento a lo que significa cultura se puede llevar específicamente a los contextos de los diferentes poblados que conforman a la provincia de Guanacaste. Por supuesto, cada uno con su particularidad, con elementos autóctonos y muy específicos. Ahí, la exhibición de productos culturales que recogen prácticas como tradiciones, música, folclore, artesanías, jergas, danzas o arquitectura cobra relevancia. De hecho, esa fue la propuesta inicial con la que comenzaron a realizarse los documentales «Las Tierras de la Princesa Nandayure» y «Una Fiesta en Liberia» producidos por Audiovisuales UNED. Como lo explica Getino (2007), "cuando una sociedad quiere revitalizar o recuperar su memoria histórica, para dinamizar políticas de cambio, promueve la producción de obras que sirvan a esa finalidad" (p. 184).

El primero de los documentales, «Las Tierras de la Princesa Nandayure» se creó con el fin de registrar la vida cotidiana de los habitantes de los distintos pueblos que componen el cantón del mismo nombre. 
El segundo audiovisual, «Una Fiesta en Liberia», comenzó a gestarse con el objetivo de recoger en sonido e imágenes una tradición con más de 300 años de antigüedad y declarada por el Gobierno de la República de Costa Rica como patrimonio cultural inmaterial. Esta importante práctica y costumbre comprende el recorrido que todos los años hacen los toros por el centro histórico de la ciudad de Liberia para llegar a una barrera tradicional y ser jugados por montadores. De esa práctica histórica, se desprende hoy un legado cultural que enmarca particulares costumbres $y$ tradiciones en constante evolución, y que se convierten en parte esencial de los habitantes de esta ciudad ubicada al noroeste de Costa Rica.

Para lograr una adecuada distribución de un producto documental y que incida en los espectadores, es fundamental referirse también a la relevancia de la cuidadosa planificación que conlleva la realización de un audiovisual; además del método minucioso con que se debe trabajar desde sus etapas de preproducción, producción y postproducción.

En el cine, tanto como en la televisión y la radio, para algunos autores (Domínguez, 2005) la preproducción es la etapa principal, puesto que ella es la primera y de la cual se derivan las otras dos. Se trata, pues, de la etapa que define el tema del documental, da pie al desarrollo de una investigación y en que se toman decisiones para los preparativos de las filmaciones. También en la preproducción se establecen presupuestos y se constituye el personal de trabajo necesario que va a conformar el equipo humano para la producción. De la misma manera, se constituye una logística de trabajo para el desarrollo de una hipótesis cuya investigación se desarrollará mediante el registro sonoro $\mathrm{y}$ en imagen en movimiento.

La segunda etapa, la de la producción, comprende propiamente el registro audiovisual bajo la guía de un director que, mediante sus decisiones en el campo, va recabando la información visual y sonora que posteriormente hilarán el documental. Pero también parte del trabajo de producción se puede generar más allá de la grabación en el campo o en un estudio. Puede existir una necesidad de generar imágenes y sonidos de todo aquello que la cámara no pudo captar, mediante otras técnicas. En el caso de la imagen, una técnica puede ser la ilustración o animación. En cuanto al sonido, es factible la grabación de una locución que explique aquello que una imagen por sí sola no puede.

En la tercera etapa, la postproducción, el registro comienza a generar un sentido narrativo. Es el hilado armonioso, coherente y estético de las imágenes y los sonidos por medio del montaje. Se suma la depuración de esas imágenes y sonidos mediante filtros de color y de corrección de audio. También ocurre la incorporación de mezclas musicales y artes gráficas que apoyen la información que originalmente se logró durante el registro y que ayuden a incrementar o a producir en el espectador sensaciones, a comprender mejor y a adentrarse más en el relato.

En congruencia con la explicación sobre las etapas de la producción, se debe notar la coexistencia dentro de un documental, como género del arte cinematográfico, de muchas otras formas de arte. Sobre el tema, Abaroa amplía:

Si además sumamos que el cine es una de las artes, la $7^{\mathrm{a}}$ de ellas, que a su vez da oportunidad a otras artes (por ejemplo, la música, la poesía, la actuación y desde luego aunque no una bella arte per se, las artes gráficas), pues el cine da oportunidad para que todas las mencionadas se beneficien directa o indirectamente.

Y si de cine se trata, qué decir de nuestro cine iberoamericano, un verdadero conjunto de culturas, música, expresiones 
idiomáticas parecidas con definiciones radicalmente diferentes. Nuestras personalidades, nuestros paisajes, nuestro concepto social, de familia, del amor, la religiosidad, las costumbres. Tenemos para dar, enseñar y repartir (p. 15).

Establecidos estos puntos, ahora se analizará el proceso de producción que tuvieron estas dos propuestas audiovisuales en sus tres fases y la posterior injerencia en su distribución.

\section{Las Tierras de la Princesa Nandayure}

El proyecto posteriormente llamado «Las Tierras de la Princesa Nandayure» comenzó en el 2014 a solicitud de la Cátedra de Historia de la UNED, con la finalidad de que se estrenara como documental durante el Festival de la Guanacastequidad que la UNED iba a desarrollar en la ciudad de Carmona, principal centro de población del cantón de Nandayure.

\section{Preproducción:}

Al ser Nandayure un cantón muy extenso y diverso, durante la preproducción, se trabajó junto a la municipalidad, con el fin de identificar personajes de los diferentes pueblos y ligarlos con actividades cotidianas propias que se desarrollaban en los lugares. Luego, durante cuatro días se recorrió el cantón en busca de historias de estos personajes.

Se realizó una investigación respecto de las locaciones más relevantes desde el punto de vista estético. También se observaron las actividades cotidianas que realizaban los posibles personajes del documental. Luego de conocer a todas las personas que el ayuntamiento había sugerido, se escogió a los personajes que, durante una eventual grabación, se les pudiera registrar una historia visual.

Se tomó también como filtro las condiciones espaciales que permitieran la colocación de cámaras y equipo de iluminación y registro sonoro. Además, durante la etapa de preproducción se identificó a los músicos oriundos del cantón para que en el proceso de grabaciones interpretaran la música que después conformaría la banda sonora de la obra audiovisual.

En cuanto a la investigación bibliográfica, se hallaron textos sobre la historia del cantón, además de la novela La venganza de Nandayure (1950), del escritor José Ramírez Sáizar, que, entre varios relatos, narra algunas leyendas ubicadas en los territorios que hoy ocupan el cantón.

En el interior de esa novela, también se encontraron pentagramas de una pieza musical llamada «Nandayure, capricho chorotega», que fue compuesta por el músico Julio Fonseca. Los pentagramas se le llevaron al compositor Francisco Piedra para que investigara la partitura, ya que prácticamente era una pieza de la primera mitad del siglo XX que había quedado en el olvido.

De la investigación bibliográfica que se hizo, como fuente primordial escrita, se utilizó la tesis Nandayure: su historia, su folclore, su gente (2003), de Vera Vargas León, que consiste en un compendio muy completo de la historia, la cultura y de los personajes del lugar.

Con base en toda esa información recabada, se organizó la logística para producción y se programó un total de tres giras de cinco días cada una, durante marzo y abril del 2015, y una gira final de dos días.

\section{Producción:}

Durante las primeras dos giras, se utilizó una sola cámara para registrar material audiovisual en alta definición. Se trabajó con una Sony XDCam, con su trípode, además de reflectores y equipo de iluminación. Durante la tercera gira, se agregó una segunda cámara XDCam para la grabación de los diferentes grupos musicales que se encontraron en 
Nandayure y cuyas interpretaciones iban a componer la banda sonora del documental.

El equipo de registro sonoro utilizado incluía una grabadora Tascam portátil, mezcladora amplificada de doce canales, tres micrófonos de condensador AKG que son ideales para canto, un boom para el registro de ambientes y dos micrófonos de solapa para las entrevistas. Asimismo, algunos accesorios como pedestales, y, en el caso específico de la grabación de un grupo de rock, cajas directas para guitarra y bajo.

Por otra parte, la grabación de la locución de la leyenda sobre Nandayure se realizó con software Protools en un estudio de audio profesional. Otro punto importante es que el maestro Francisco Piedra, luego de varias semanas de estudio de la partitura de la pieza musical «Nandayure, capricho chorotega», la interpretó en un piano eléctrico en estudio de audio, también con software Protools.

Adicionalmente, para narrar en imagen la leyenda de la princesa Nandayure, se resumió los textos escritos de José Ramírez Saizar en un relato sonoro de cuatro minutos y se crearon ilustraciones animadas como recurso en imagen.

\section{Postproducción:}

La edición y la colorización se realizaron en una computadora iMac en software Final Cut 7. Para la masterización del audio, se utilizó software Soundforge y el paquete Universal Audio para postproducción.

Tabla 1 Ficha técnica del documental «Las tierras de la Princesa Nandayure», mediateca de Audiovisuales UNED, 2015.

\begin{tabular}{|l|l|}
\hline Número de programa & 793 \\
\hline Fecha de producción & Julio 2015 \\
\hline Nombre del programa & Las tierras de la princesa Nandayure \\
\hline Duración & $50^{\prime} 14^{\prime \prime}$ \\
\hline Género & Documental \\
\hline Descriptores & $\begin{array}{l}\text { Guanacaste, Nandayure, princesa indígena, Chorotega, } \\
\text { Cerro Azul, Berrugate, Trapiche, Hacienda, Café, } \\
\text { Marimba, Nicoyán, Trio }\end{array}$ \\
\hline Tema & Historia y vida cotidiana en el cantón de Nandayure \\
\hline Objetivo & $\begin{array}{l}\text { 1. Documentar la vida cotidiana en el cantón de } \\
\text { 2. Recopilar la historia del cantón de Nandayure }\end{array}$ \\
\hline $\begin{array}{l}\text { A unos 210 kilómetros al noroeste de San José, Costa } \\
\text { Rica se encuentra el cantón de Nandayure. El nombre de } \\
\text { este lugar proviene de una princesa Chorotega que } \\
\text { significa "cerro alto". Las tierras de esta antigua } \\
\text { soberana indígena hoy son bañadas por las aguas del } \\
\text { Golfo de Nicoya en un extremo y en el otro por el mar } \\
\text { abierto del Océano Pacifico. Sitio de contrastes } \\
\text { geográficos, pues yace el cerro más alto de la Península } \\
\text { de Nicoya y se cuenta con la única isla que le pertenece } \\
\text { a la provincia de Guanacaste. Entre las dos costas y el } \\
\text { pie del cerro, viven los nuevos hijos de Nandayure. } \\
\text { Hombres y mujeres que bregan todos los días para }\end{array}$ \\
\hline
\end{tabular}




\begin{tabular}{|l|l|}
\hline & $\begin{array}{l}\text { ganarse la vida entre trapiches, cafetales, haciendas } \\
\text { ganaderas, puertos pesqueros y hornos hechos de barro. }\end{array}$ \\
\hline Solicitado por & $\begin{array}{l}\text { Alonso Rodríguez, Cátedra de Historia, Escuela de } \\
\text { Ciencias Exactas y Naturales }\end{array}$ \\
\hline Realización & José Pablo Castillo Valverde \\
\hline Productores & $\begin{array}{l}\text { José Pablo Castillo Valverde, Flor de Lis Mayorga y } \\
\text { Damaris Patricia Méndez }\end{array}$ \\
\hline Guion y argumentación & José Pablo Castillo Valverde \\
\hline Entrevistados & $\begin{array}{l}\text { Vera Beatriz Vargas León, Porfirio Quesada Ugalde, } \\
\text { Fernando González Méndez, Noemy Castrillo Ledezma, } \\
\text { José Manuel Castillo Rojas, Ventura Chávez Barquero, } \\
\text { Santos Félix Vásquez Montiel, Maria Micaela Guevara } \\
\text { Gómez, Mario Quirós Loría, Eliseo Fajardo Diez, Luis } \\
\text { Fernando Badilla Alfaro, Juan Isidro Vargas Espinoza, } \\
\text { Oscar Mario Villalobos Carrillo, Miriam Martínez } \\
\text { Godoy, Wilson Pérez Rivas, Zeneida Trejos Rosales y } \\
\text { Jesús Alberto Vargas Vargas }\end{array}$ \\
\hline Fotografía y cámara & Santiago Martínez y Enrique Vega \\
\hline Sonido & Benigno Robleto \\
\hline Edición & José Pablo Castillo Valverde \\
\hline $\begin{array}{l}\text { Diseño gráfico, ilustración } \\
\text { y animación }\end{array}$ & \begin{tabular}{l} 
Carmen Vargas \\
\hline
\end{tabular} \\
\hline
\end{tabular}

\section{Una Fiesta en Liberia}

Por su parte, la producción del documental «Una Fiesta en Liberia» comenzó a gestarse en septiembre del 2015, por una solicitud del Centro Universitario de Liberia y de la Cátedra de Historia de la UNED, a raíz de una inquietud de la Asociación para la Cultura de Liberia. Dicha organización notó la necesidad de registrar imágenes profesionales del tope de toros de Liberia, tradición que data de hace más de 300 años y que viene de la época de las haciendas guanacastecas. Los miembros de la asociación tenían la inquietud de que las nuevas generaciones pudieran conocer la historia relacionada con el tope de toros.

\section{Preproducción:}

La investigación bibliográfica para la producción del documental incluyó información sobre la historia de la ciudad de Liberia. También sobre otras temáticas como la arquitectura de las edificaciones más importantes de la ciudad, principalmente la Ermita de Nuestro Señor de la Agonía, de la cual se tomó buena cantidad de información del libro del mismo nombre, escrito por la historiadora Gina Rivera y el arquitecto Erick Chávez.

Sin embargo, en razón de ser el tope de toros de Liberia una tradición de la que no se encontró mucho material bibliográfico, se acudió a la fuente testimonial. Se realizó una primera sesión de entrevistas con el profesor de historia Ronald Martínez Villareal, del Museo Nacional, y con la historiadora liberiana de la Universidad de Costa Rica (UCR), Gina Rivera.

Al tratarse el tope de toros de una tradición forjada en las haciendas ganaderas por medio del trabajo de los sabaneros, se entrevistó a personas que en su juventud habían trabajado y aprendido algunos oficios junto a esos antiguos personajes de las haciendas guanacastecas. Cabe destacar que el trabajo de sabanero ya actualmente se 
encuentra desaparecido. El objetivo del tope de toros era llevar los bovinos desde las haciendas ganaderas hasta la barrera, lugar donde se hacían las fiestas cuya atracción principal eran las «montaderas». El trabajo de llevar los animales les correspondía a los sabaneros y ellos mismos montaban los toros.

Por esa razón, se contactó a personas como Manuel Ángel Martínez, Jorge Humberto Acevedo, Julián Bustos, Luis Ángel Brizuela, Jesús Montoya y Jesús Fernando Bustos, que trabajaron al lado de estos sabaneros.

Con el objetivo de abordar la temática de la arquitectura que rodea a la ciudad de Liberia y por donde pasa el tope de toros, se complementó la información bibliográfica con entrevistas previas al arquitecto Érick Chávez; a la profesora Mélida Obando, en el caso específico de la Ermita de Nuestro Señor de la Agonía; y al empresario Warren Meza, en cuanto al hotel Liberia.

Desde un inicio, se pensó que toda la banda sonora fuera música guanacasteca y para tal fin se entrevistó a Ronald Estrada, director de la Banda de Conciertos de Guanacaste. La información se complementó con investigación bibliográfica sobre la vida y obra de dos de los autores guanacastecos más reconocidos: Jesús Bonilla y Héctor Zúñiga.

En el caso específico de la mascarada, que también acompaña al tope de toros, se entrevistó a Joaquín Palacios, ganador del Certamen «Nuestras Artesanías Tradicionales» (2013) que organiza el Ministerio de Cultura y Juventud. Palacios aún se dedica a la creación de máscaras tradicionales.

En el marco de la investigación, se logró recopilar material fílmico de la ciudad de Liberia realizado en cine de 8 milímetros. Las imágenes habían sido registradas de manera aficionada en la década de 1960 por el señor Eduardo Arata. En el material fílmico, había imágenes del tope de toros. También se descubrieron algunas fotografías antiguas de la ciudad de Liberia, de principios del siglo XX.

Esos elementos encontrados en la investigación permitieron vislumbrar que había potencial de un gran documental, enmarcado, en su mayoría, en un entorno de tan solamente unos cuantos kilómetros a la redonda porque la generalidad de los acontecimientos y situaciones ocurrían en la ciudad de Liberia. Sobre el caso específico de las filmaciones documentales en la ciudad como entorno, Irigaray (2014) afirma que "pensar a la ciudad como una plataforma narrativa transversal implica construir la historia en una territorialidad expandida. Múltiples lenguajes, soportes, dispositivos y géneros son puestos al servicio de un ecosistema de relatos convergentes" (p. 116).

Esta fue una particularidad de «Una Fiesta en Liberia» y muy diferente a «Las Tierras de la Princesa Nandayure» pues en Liberia la mayoría del relato y las interrelaciones ocurre en los alrededores de la ciudad, mientras que en Nandayure se toman una o dos historias de unos diez pueblos del cantón, que se hallan geográficamente separados.

\section{Producción:}

Seis giras fueron organizadas en enero, febrero, marzo, abril y mayo del 2016; en total, fueron 35 días de trabajo de filmación. El objetivo era registrar los topes de toros, la construcción de la barrera, la elaboración de mascaradas, detalles del puente real y de la ciudad, las «montaderas», los sitios arquitectónicos importantes, una fiesta tradicional liberiana, vistas panorámicas y la fauna que aún se conserva en las inmediaciones de la ciudad. Igualmente, fue preciso filmar los trabajos que todavía se preservan de las antiguas haciendas ganaderas y los oficios que se heredaron de los sabaneros. Además, fueron grabadas algunas entrevistas. 
Para estas grabaciones, se utilizó una cámara Sony F55 en $4 \mathrm{~K}$ con juegos de lentes cuyas ópticas iban desde un angular hasta un teleobjetivo 300. Asimismo, para algunas filmaciones, se incorporó un duplicador. También se empleó dos cámaras Sony XDCam de alta resolución. Una de ellas iba montada sobre un brazo metálico de mediano alcance. Y fueron usados reflectores y equipo de iluminación durante las grabaciones nocturnas y en interiores.

Del mismo modo, se hizo el registro visual y sonoro de unas doce piezas que interpretó la Banda de Conciertos de Guanacaste con el objetivo de incluirlas dentro de la banda sonora y que, a la vez, funcionara como un el hilo conductor visual y auditivo del documental. En algunas de estas interpretaciones colaboraron, junto a la banda, el tenor Ernesto Rodríguez y la soprano Sasha López.

Esta filmación de la interpretación de la banda cumplió un segundo objetivo. Se pretendía que la grabación generara un producto adicional e independiente del documental. En este caso, sería el concierto completo de la banda. Se utilizó el mismo equipo fílmico que se había usado antes; pero una de las cámaras XDCam tuvo que cambiarse por una Sony NEX-EA50H; además, se le adicionó una cámara Go Pro. Este mismo equipo fue utilizado para la grabación de la tradición de la «ternerada».

\section{Postproducción:}

Se seleccionó parte del material fotográfico encontrado durante la etapa de investigación; dependiendo de su estado y calidad, se pasó por un proceso de retoque y restauración digital y animación con software de Adobe Photoshop y Adobe After Effects. En adición, se produjo ilustraciones de personajes importantes para la cultura y la historia de Liberia, de los que se carecía de fotografías o sí existía material pero no con la resolución necesaria. Este trabajo se realizó con software Adobe Ilustrator y su posterior animación se llevó a cabo en Adobe After Effects.

Se utilizó parte del material fílmico en $8 \mathrm{~mm}$ de los años 60, específicamente en lo que concierne al tope de toros, así como imágenes de la ciudad de Liberia y de playas del Coco.

El registro audiovisual que se realizó, se editó en una computadora Mac Pro con software Adobe Premier Pro. Al haberse trabajado con cámaras de diversa calidad, se hizo un minucioso proceso de corrección de color con software DaVinci Resolve. La masterización del sonido se hizo con software Soundforge y el paquete Universal Audio para postproducción sonora

Tabla 2 Ficha técnica del documental «Una Fiesta en Liberia», mediateca de Audiovisuales UNED, 2017.

\begin{tabular}{|l|l|}
\hline Referencia Mediateca & 818 \\
\hline Código & Una Fiesta en Liberia \\
\hline Nombre del programa & $\begin{array}{l}\text { Historia, costumbres, tradiciones y arquitectura de } \\
\text { Liberia mediante el recorrido del tope de toros }\end{array}$ \\
\hline Género del programa & Documental \\
\hline Entidades solicitantes & $\begin{array}{l}\text { Alonso Rodríguez, Cátedra de Historia; Lynette } \\
\text { Camacho, directora del Centro Universitario de Liberia }\end{array}$ \\
\hline $\begin{array}{l}\text { Asignatura o curso donde } \\
\text { se va a utilizar }\end{array}$ & Cátedra de Historia \\
\hline
\end{tabular}




\begin{tabular}{|c|c|}
\hline Especialista en contenidos & Ronald Martínez Villarreal \\
\hline \multicolumn{2}{|l|}{ Referencia Programa } \\
\hline Cines donde se transmitió & Multicines Liberia \\
\hline Fecha de producción & Julio 2017 \\
\hline Duración & 1 hora 38 minutos \\
\hline Realización & José Pablo Castillo Valverde \\
\hline Productores & José Pablo Castillo Valverde, Lynette Camacho \\
\hline Guion y argumentación & José Pablo Castillo Valverde \\
\hline Dirección de fotografía & Marco Millape \\
\hline Fotografía & $\begin{array}{l}\text { Marco Millape, Nicoa Ríos, Alex Rojas, Santiago } \\
\text { Martínez, Enrique Vega, Andrés Alvarado y Manrique } \\
\text { Vargas }\end{array}$ \\
\hline Sinopsis & $\begin{array}{l}\text { Liberia, Guanacaste; ciudad fundada como centro } \\
\text { político y administrativo de una región históricamente } \\
\text { dominada por extensas haciendas ganaderas. Los } \\
\text { conquistadores españoles describieron este territorio } \\
\text { como "El paraíso de Mahoma", debido a su belleza } \\
\text { natural. Allí, hace más de } 300 \text { años se comenzó a gestar } \\
\text { el marco cultural que dio origen a la tradición del Tope } \\
\text { de toros, hoy declarado por el gobierno de la República } \\
\text { de Costa Rica como patrimonio cultural inmaterial. De } \\
\text { las haciendas se traían los mejores ejemplares para la } \\
\text { monta y se juntaban en las cercanías del río Liberia. } \\
\text { Desde ese sitio se enrumbaban hacia la ciudad } \\
\text { paseándose por entre calles de cascajo blancuzco y casas } \\
\text { de barro, y resguardados por los mejores sabaneros de } \\
\text { cada una de las extensas propiedades ganaderas. El } \\
\text { término del recorrido era la barrera, construida al otro } \\
\text { lado del poblado. En este reducto de madera, los } \\
\text { gallardos hombres mostraban sus habilidades en la } \\
\text { monta y el manejo de los bravos bovinos. De esa práctica } \\
\text { histórica, se desprende hoy un legado cultural que } \\
\text { enmarca particulares costumbres y tradiciones en } \\
\text { constante evolución, y que se convierten en parte } \\
\text { esencial de los habitantes de la mítica "Ciudad Blanca" } \\
\text { del noroeste de Costa Rica. }\end{array}$ \\
\hline Descriptores & $\begin{array}{l}\text { Liberia, tope, toros, redondel, montaderas, historia, } \\
\text { costumbres, Guanacaste, barrera, arquitectura, colonial, } \\
\text { música, banda, puente real y ermita }\end{array}$ \\
\hline Codec master & Apple ProRes 422 HQ, Linear PCM \\
\hline Edición & José Pablo Castillo Valverde \\
\hline Idioma original & Español \\
\hline Subtítulos/Lesco & Inglés \\
\hline Formato original & XAVC y XDcam \\
\hline Interpretación musical & $\begin{array}{l}\text { Banda de Conciertos de Liberia (intérpretes: Sasha } \\
\text { López y Ernesto Rodríguez) }\end{array}$ \\
\hline Entrevistados & $\begin{array}{l}\text { Gina Rivera Hernández, Ronald Martínez Villareal, } \\
\text { Ronald Estrada Sánchez, Manuel Ángel Martínez } \\
\text { Abarca, Jorge Humberto Acevedo Álvarez, Julián }\end{array}$ \\
\hline
\end{tabular}




\begin{tabular}{|l|l|}
\hline & $\begin{array}{l}\text { Bustos Mendoza, Erick Chávez, Mélida Obando Viales, } \\
\text { Warren Meza Valverde, Miguel Fajardo Corea, Joaquín } \\
\text { Palacios Loaiciga, Nuria Cuadra Clachar, Luis Ángel } \\
\text { Brizuela Cortez, Jesús Montoya Huertas y Jesús } \\
\text { Fernando Bustos Peña }\end{array}$ \\
\hline Sonido & Benigno Robleto \\
\hline Diseño y animación & Laura Ruiz, Gustavo Godínez y José Mario Quesada \\
\hline Colorización & Carmen Vargas \\
\hline
\end{tabular}

\section{Promoción, difusión e incidencia de los documentales}

La metodología de producción que se utilizó para ambos documentales ha resultado en una injerencia para su difusión en las comunidades. Además, ha llegado al campo internacional en diferentes festivales y concursos de cine en los cuales se ha inscrito.

En el caso de «Las Tierras de la Princesa Nandayure», se promocionó su estreno únicamente en el marco del XI Festival Académico Cultural de la Guanacastequidad, que la UNED organizó para el 2015 en ese cantón. Dicho festival fue concebido desde la Cátedra de Historia de la Escuela de Ciencias Sociales y Humanidades
(ECSH), la misma dependencia que solicitó la producción del documental.

«Las Tierras de la Princesa Nandayure» se estrenó el miércoles 22 de julio del 2015 a las 7:00 p.m. en el anfiteatro de Nandayure. Imperó un mal tiempo en la zona debido a una fuerte lluvia que cayó; pero aun así, el anfiteatro se abarrotó de espectadores y el documental tuvo una gran acogida entre el público presente. Se calcula que asistieron unas 400 personas.

Posteriormente, no se ha vuelto a proyectar la filmación en el lugar. Sin embargo, el documental se subió al canal de YouTube de Audiovisuales UNED y rápidamente para el 2016 se convirtió en el video más visto del sitio. Para el 8 de agosto del 2016, tenía un total de 2272 visitas.

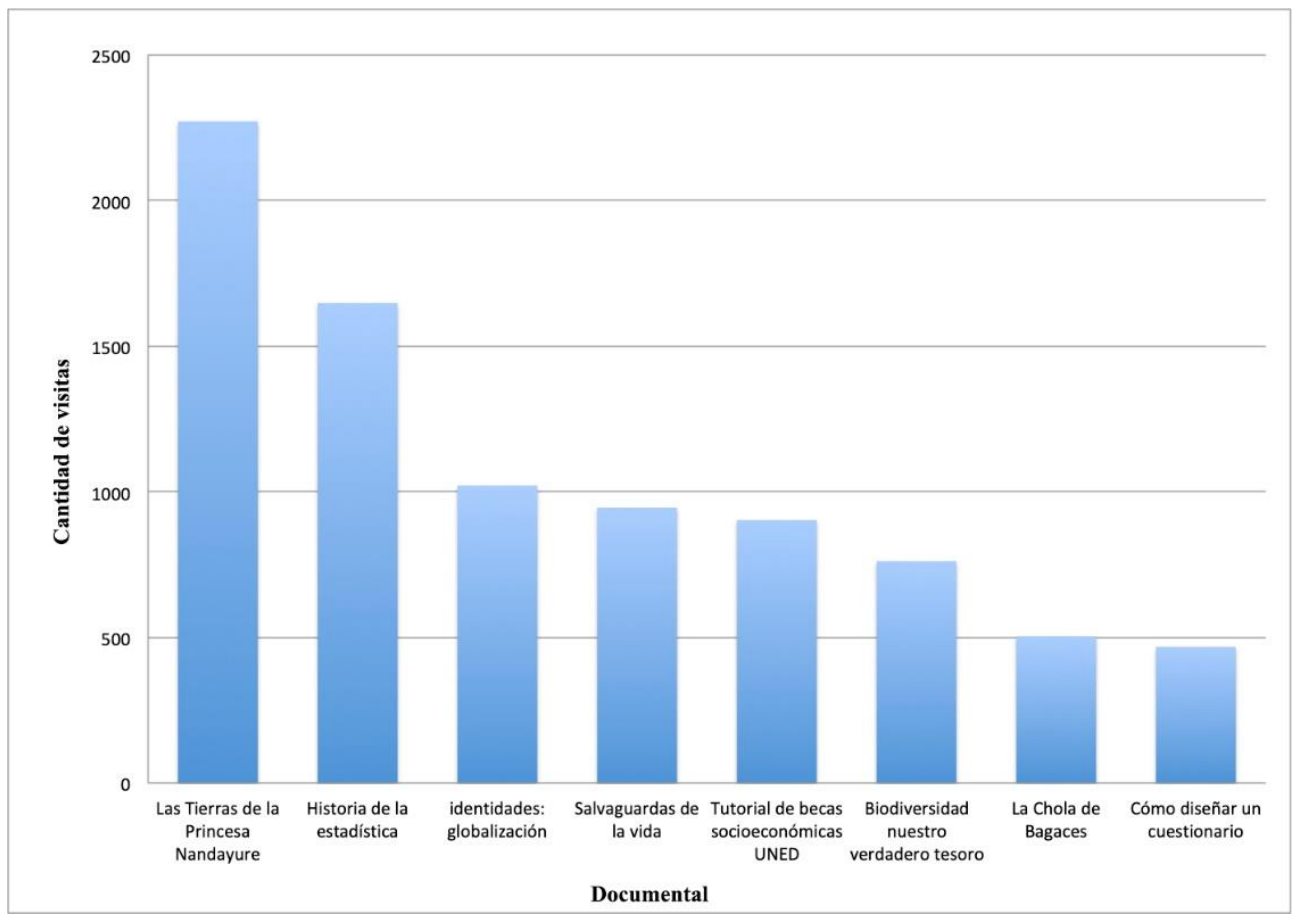


Figura 1 Top 10 de videos más vistos en sitio de Youtube de Audiovisuales. Fuente: Google Analytics, Canal de Youtube de Audiovisuales UNED, 2016.

Para agosto del 2019, ha alcanzado un total de 7803 visualizaciones. Al notar que comenzó a tener un auge en la web, se subtituló a inglés con el primer objetivo de enviarlo a concursar en premios y festivales de cine internacionales ¿Por qué esto? Abaroa (2018) hace una reflexión primero generalista de las sociedades actuales y después enraizada específicamente en los productos audiovisuales, acerca de la importancia de los premios dentro de la industria. Básicamente, establece la existencia de galardones y de la necesidad de que los productos entren a estos concursos porque al ser humano, ya por naturaleza le gusta competir.

Por lo tanto, el mismo autor establece que los premios le dan un plus de respeto a una obra audiovisual; primero, porque fue premiada por un jurado $\mathrm{y}$, segundo, porque ese jurado casi siempre se conforma por personas reconocidas en la materia. Entonces, si el jurado es respetado, el premio es respetado, lo cual, por ende, deriva en que la obra audiovisual también sea respetada.

Además de estas dos razones existen otras como, por ejemplo, el nombre del premio, que brinda notoriedad internacional. De la misma manera, en este tipo de premiaciones, normalmente, siempre hay ceremonias con un cierto glamour y una cobertura de medios. El recinto donde se entrega un premio da la percepción de éxito, poder y fuerza que se trasladan a la obra audiovisual galardonada o, por lo menos, nominada.

Por estos motivos, más el objetivo de colocar a la UNED en la palestra internacional, se inscribió tanto "Las Tierras de la Princesa Nandayure», como «Una Fiesta en Liberia» en diferentes concursos de cine.
Por alguna razón no explicable a la gente le gusta saber que alguien compitió y fue premiado... ¿Y qué decir de los mercados que están fuera del continente? Francia, China, Japón, Australia, Egipto, Turquía, países ávidos de conocer nuestra cultura, de consumir lo que hacemos. Solo tenemos que recordarles con frecuencia que existimos (Abaroa, 2018, pp. 14-16).

Hay que resaltar, además, que los premios son una muy buena plataforma de mercadeo, incluso para obras audiovisuales cuyo fin no sea estrictamente las ventas.

Ya para el 19 de septiembre del 2016 se galardonó a «Las Tierras de la Princesa Nandayure» con el Premio en Producción Audiovisual René Picado Esquivel a la Mejor Producción Audiovisual, que otorga el Colegio de Periodistas de Costa Rica (COLPER).

En el 2018, recibió el premio al Mejor Largometraje Documental (Best Feature Documentary) durante el Festival de Cine Master Doc (Master Doc Film Festival) que se llevó a cabo los días 20 y 21 de abril de ese año. Este festival es producido por la organización Movie Screen Pro, que tiene su sede en Los Ángeles, California.

En octubre del 2018, también fue galardonado con el segundo lugar del premio al Mejor Largometraje Documental durante el Festival de Cine de los Doce Meses, que se celebró en la ciudad de Cluj-Napoca en Rumanía.

Fue selección oficial del Festival de Cine de la Ciudad de Erie (Erie International Film Festival) en Pensilvania, Estados Unidos, en su edición 2018, ocurrida del 13 al 22 de diciembre de ese año.

Asimismo, fue selección oficial de la quinta edición del Festival de Cine del 
Golfo de Nápoles (Gulf of Naples Film Festival) y se exhibió en esa ciudad de Italia el 17 de mayo del 2019, dentro del complejo de la Iglesia de Santa María del Parto, ubicada en la vía Mergellina de Nápoles, la ciudad más poblada del sur de Italia.

En este mismo país, el documental también fue parte de la selección oficial de los premios Prisma 2019, galardón que se otorga en Roma. Un año antes, en febrero del 2018 había estado nominada a Mejor Película Largometraje en el Festival Mensual de Películas (Monthly Film Festival) con sede en Escocia, Reino Unido; destaca el hecho de que siendo del género documental, compitió incluso contra ficciones.

Asimismo, el audiovisual estuvo nominado a Mejor Largometraje Documental (Best Documentary) y a Mejor Película de un País del Caribe (Best Film Caribbean) en el IV Festival Internacional Nollywood de Cine de Toronto (Toronto International Nollywood Film Festival), que se llevó acabo en septiembre del 2019. En esta última categoría se llevó el galardón.

Por el momento, con estos sellos oficiales de festivales y concursos ha quedado impregnado el documental «Las Tierras de la Princesa Nandayure»:
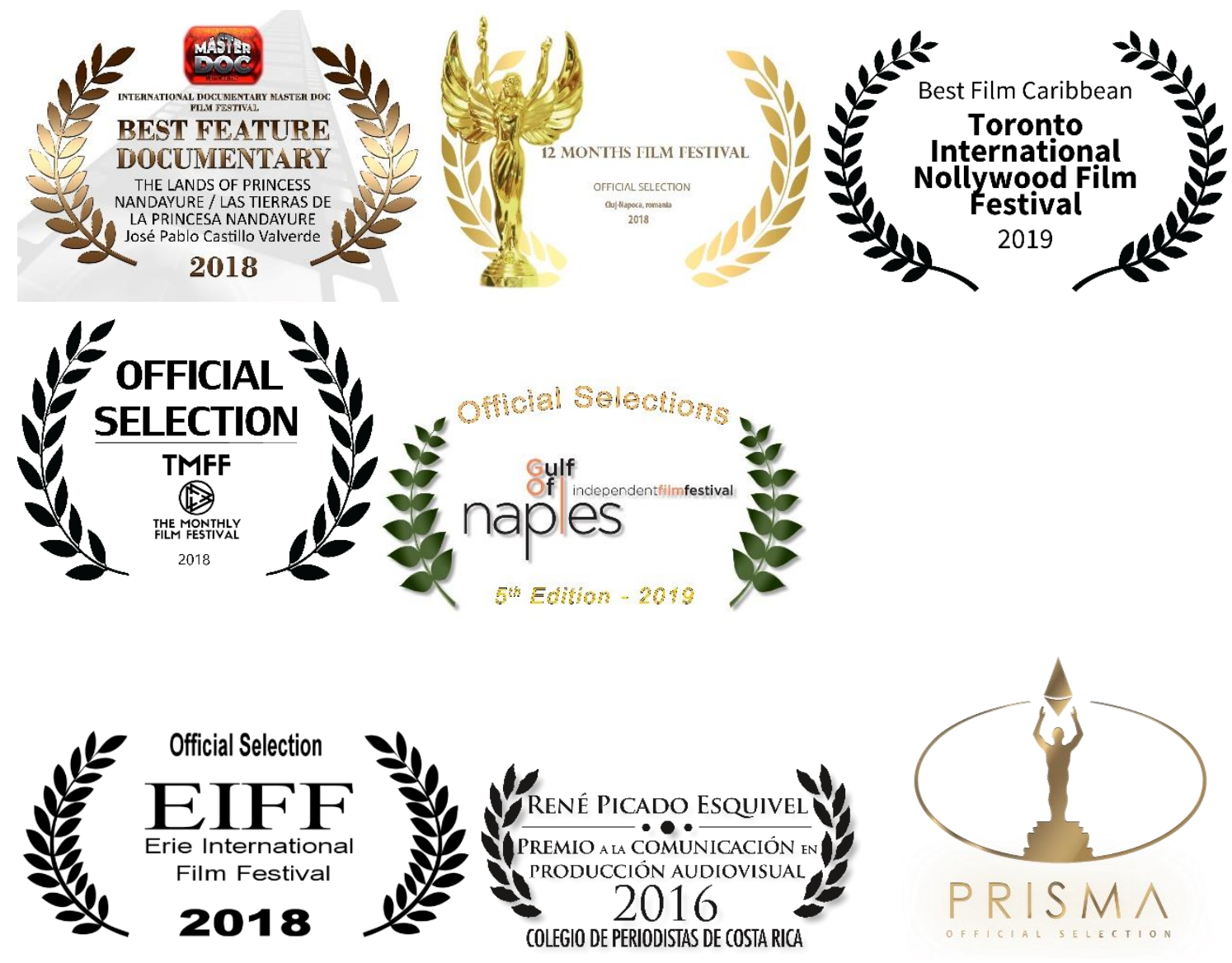

Figura 2 Laureles otorgados a «Las Tierras de la Princesa Nandayure» en concursos y festivales de cine nacionales e internacionales. Fuente: Archivos de Audiovisuales UNED, 2015- 2019.

En cuanto al documental «Una Fiesta en Liberia», se buscó promocionar más el estreno y otras presentaciones, tomando en cuenta el auge de las redes sociales.
Esto también porque Liberia, al ser la cabecera de provincia, es un centro mayor de población. Se forjó una alianza entre Audiovisuales UNED, la Asociación para 
la Cultura de Liberia y el Comité Cantonal de Deportes de Liberia para estrenar el documental en el estadio mundialista Edgardo Baltodano Briceño para el sábado 19 de agosto del 2017. Se lanzó una campaña por Facebook durante 13 días, desde el 7 hasta el 19 de agosto, en la cual se invirtieron 60 mil colones para promocionar el evento. La finalidad era que la información se distribuyera en dispositivos electrónicos por ubicación desde el centro de Liberia en un radio de unos 10 kilómetros. En el anuncio se colocó la información del estreno y además un trailer (video del anuncio como próximo estreno). En el caso particular de esta promoción, es crucial analizar los datos que arrojó y tomarlos en cuenta para futuros proyectos. Con respecto al alcance de la publicación, entendiendo alcance como el número de usuarios que observaron la promoción del estreno, se llegó a un buen número pues fue visto por 25190 personas. Otra cifra interesante está referida a las impresiones; es decir, la cantidad de veces que la publicación fue vista: un total de 106581 ocasiones. Por lo tanto, si se calcula un promedio entre el alcance y las impresiones, entonces cada persona que observó el anuncio en su Facebook, lo volvió a hacer tres veces más. Es interesante que casi 50\% $(48,177 \%)$ de las personas que alcanzó la publicación se encontraban en un rango de edad de entre los 25 y los 44 años. Además, fue visto en cuanto a la relación hombre - mujer, por mil féminas más.

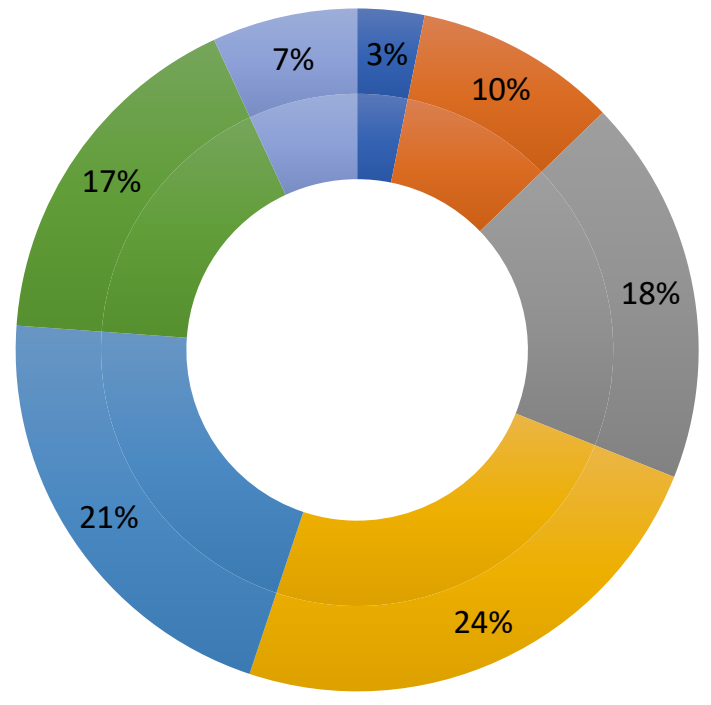

Rango

13-17

18-24

25-34

35-44

45-54

- 55-64

$65+$

Figura 3 Porcentaje Total de reproducciones del trailer de «Una Fiesta en Liberia» en Liberia y sus alrededores durante la promoción en Facebook desde el 7 hasta el 19 de agosto del 2017 (segmentación por edades). Fuente: Facebook de Audiovisuales UNED, 2017.

Estos datos arrojan información relativa a públicos meta potenciales y formas de lenguaje y enfoques en los que se pueden encauzar futuros trabajos audiovisuales.

Otra información significativa es con respecto al trailer, pues este fue reproducido 19358 veces durante los doce días de promoción. E1 $76 \%$ de quienes vieron el video, lo hicieron desde un teléfono inteligente con sistema Android.

Un porcentaje considerable también lo visualizó desde un teléfono Iphone (13\%). E1 5\% lo observó en una tableta Android y otro $5 \%$ en una tableta Ipad. Un porcentaje mínimo lo vio por dispositivos como Ipod y otros. 


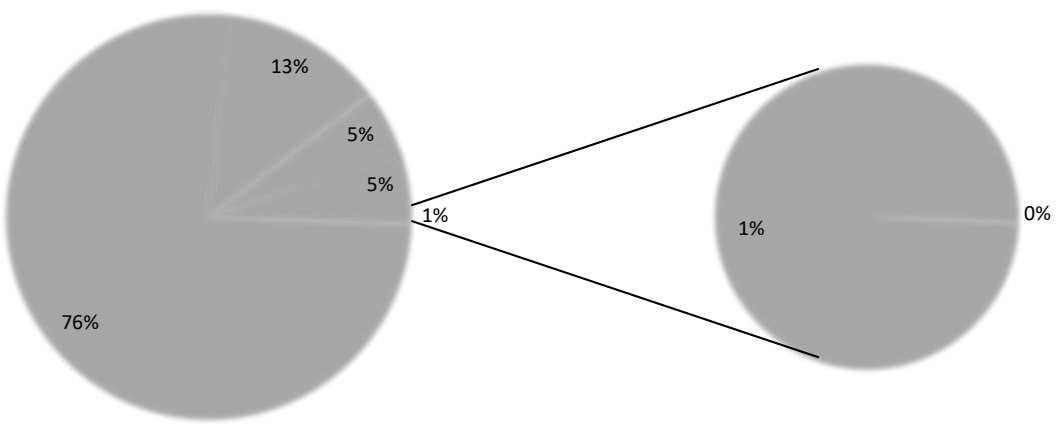

Figura 4 Dispositivos en los que se reprodujo el trailer de «Una Fiesta en Liberia» en Facebook durante los días de promoción del estreno del 7 al 19 de agosto del 2017. Fuente: Facebook de Audiovisuales UNED, 2017.

Se nota, entonces, que una gran mayoría de usuarios vieron el trailer en su aparato personas que lo hicieron en su de teléfono celular en comparación con las computadora.

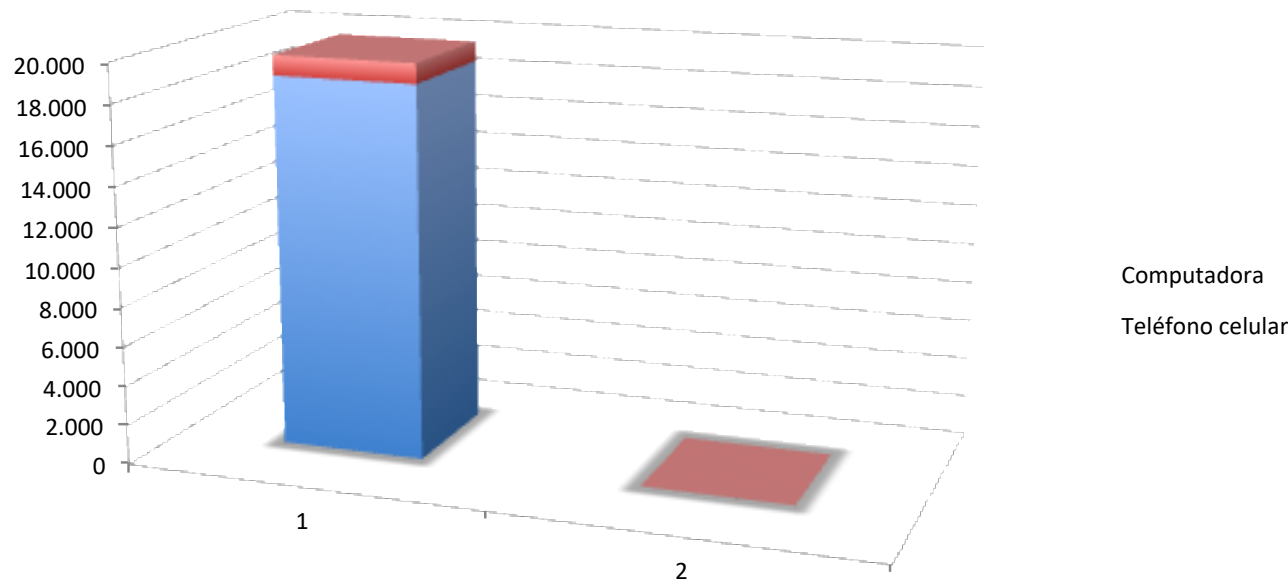

Figura 5 Plataforma de dispositivos en los que se vio la publicación promocional del estreno de «Una Fiesta en Liberia». Fuente: Facebook de Audiovisuales UNED, 2017.

En la actualidad, pautar en Facebook permite aumentar las interacciones $\mathrm{y}$ cuando esto sucede, se genera un tipo de empatía con la actividad que se está promocionando.

El sistema (Facebook) fue creado para difundir anuncios que puedan llamar la atención de una manera tan efectiva como lo que las compañías de internet llaman contenido orgánico - publicaciones de amigos, familiares y otras entidades con las cuales los usuarios están conectados.
Efectivamente, los anuncios aparecen de la misma manera como lo hace el contenido orgánico, con la diferencia de que hay dinero invertido en publicidad (Metz, 2017).

De esta manera, un dato relevante consiste en las reacciones que se producen ante la actividad que se va a realizar porque por en los emoticones que los usuarios utilizan, se puede inferir un interés ante el estreno del documental. En este caso, 232 
personas evidenciaron reacciones ante la publicación.

Asimismo, unas 137 personas compartieron la publicación con otros contactos en su Facebook. Hubo 18 comentarios por la actividad, la mayoría referida a un interés por asistir, o bien con felicitaciones y expectativa en cuanto al estreno.

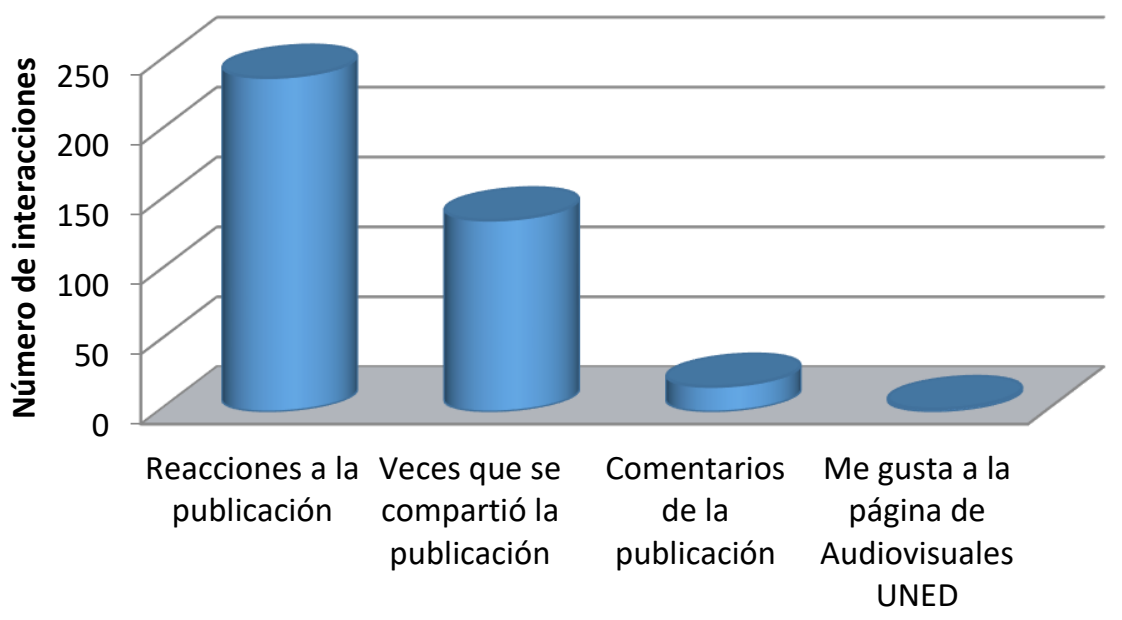

Tipo de interacción

Figura 6 Interacción con la publicación promocional del estreno de «Una Fiesta en Liberia». Fuente: Facebook de Audiovisuales UNED, 2017.

El día del estreno se reservó la mitad del estadio para presentar el documental en un formato anfiteatro. Se calculó la cantidad de las personas que asistieron a la actividad por el número de sillas utilizadas. "Una Fiesta en Liberia» fue vista en su estreno por unas 800 personas, lo cual es, probablemente, hasta hoy, el número más alto de asistentes a una actividad de estreno de documental de la UNED. Para esa presentación se puso a la venta 200 copias que incluían un DVD y un Blu-ray en el mismo empaque. Todas se vendieron a la módica suma de 5 mil colones (aproximadamente 9 dólares estadounidenses, según el tipo de cambio en el 2019), con el objetivo de difundir más el contenido del documental respecto de las tradiciones y costumbres de Liberia.

Una vez exhibida la filmación por primera vez, junto a la Asociación para la Cultura de Liberia se organizó un reestreno en una sala de cine y su consecuente exhibición para la cartelera del mes de septiembre. Para ello, se recibió la colaboración gratuita de Multicines Liberia. Lo anterior implicó que el documental tuviera que ser pasado a formato DCP, el que actualmente utilizan los cines para su distribución. Además, se confeccionaron afiches para colocar en los vitrales de la cadena de cines para que las personas que transitaran por el Mall Centro Plaza de Liberia se enteraran de las proyecciones. ¿Por qué un trabajo realizado en un aparato de producción de una universidad tuvo particular interés en que se pudiera exhibir en el cine, en especial un documental sobre temas con un enfoque muy particular hacia las tradiciones de la ciudad de Liberia? La respuesta es la ventaja de la presencia de esta cadena de cines en la misma ciudad donde se filmó la mayor parte del documental. Esta respuesta se puede apoyar también en algunas cifras de la industria. Si tomamos en cuenta que en el 2017, en el mundo, la asistencia al cine sumó 7576 millones de boletos vendidos y hasta el 2019 con una tendencia ascendente. En Costa Rica para el 2017, se sumaron 7.6 millones de boletos vendidos (European Audiovisual 
Observatory, 2018). Entonces, la asistencia al cine para ir a ver una película todavía es una atracción; y, en este caso específico, una película sobre la ciudad misma donde se habita.

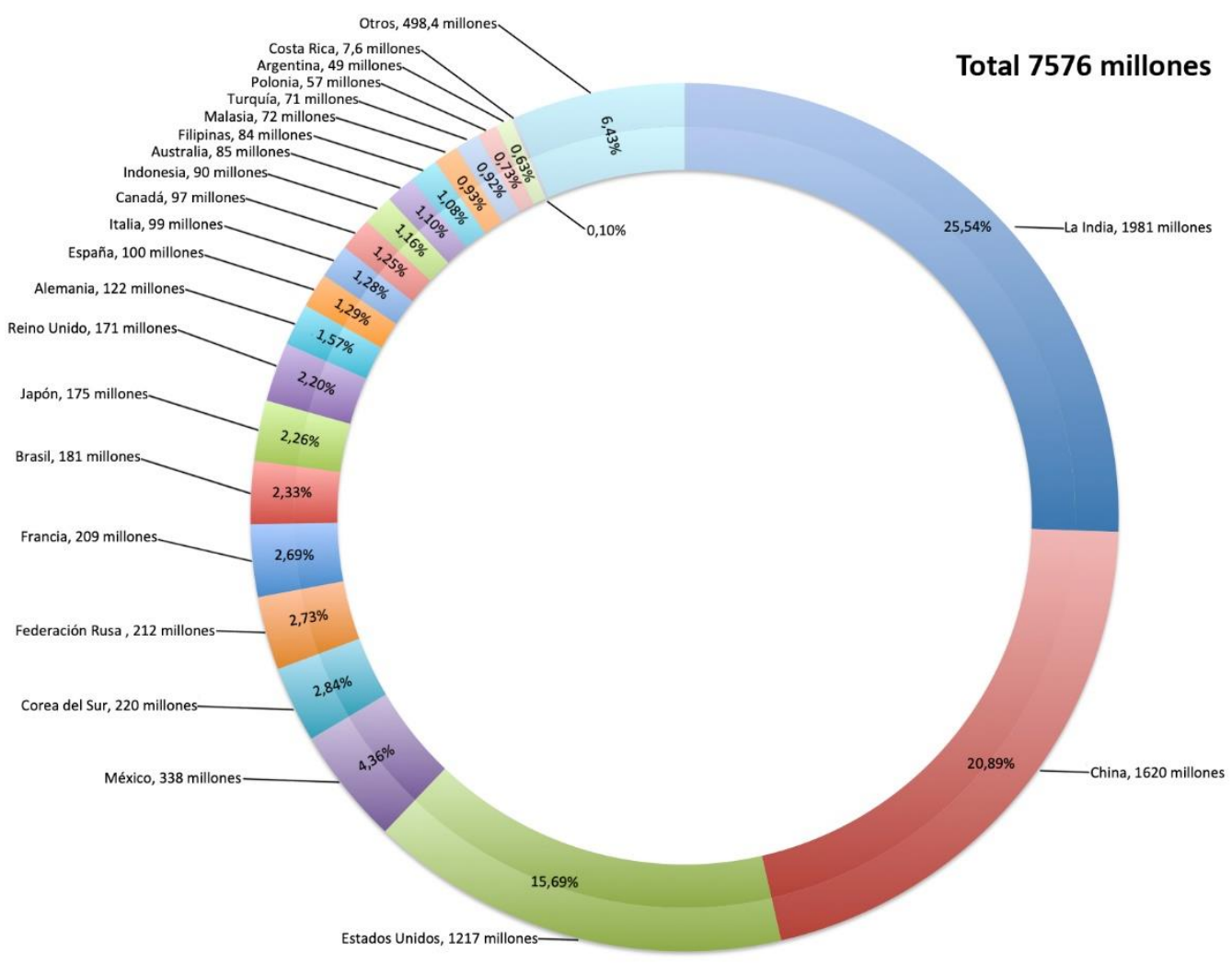

Figura 7 Cantidad de asistencia a los cines por país en millones de personas. Fuente: Focus 2018, European Audiovisual Observatory, 2018.

El reestreno del documental «Una Fiesta en Liberia» se efectuó en función especial en Multicines Liberia el 31 de agosto del 2017 a las 7:00 p.m. Se proyectó la película en exclusiva a invitados especiales de la comunidad y la UNED recibió la dedicatoria oficial de la XXXI Semana Cultural Liberia Ciudad Blanca 2017, por parte de la Municipalidad de Liberia y de la Asociación para la Cultura de Liberia, gracias a la realización del audiovisual.

Es de particular atención que la calidad de la imagen y el sonido que se observó y se escuchó en el cine fue espectacular y se podría decir que cautivó a los presentes que, dependiendo de la escena del documental, reían o lloraban.

Posteriormente, se organizó junto con la empresa Multicines Liberia y la
Asociación para la Cultura de Liberia una serie de funciones gratuitas en las salas de cine mencionadas. La programación se concretó para las semanas del 31 de agosto al 26 de septiembre. Más de 2500 personas asistieron a observar el documental. Incluso hubo algunos días en que, por la alta demanda, Multicines Liberia proyectó el documental en tres salas simultáneamente.

Aparte de los ciudadanos liberianos, gran cantidad de estudiantes observaron el documental. Los jóvenes provenían de los siguientes centros educativos: Academia Teocali, Centro Educativo CENIT, Colegio Académico Deportivo de Cañas Dulces, Liceo Laboratorio de Liberia, Escuela Ascensión Esquivel, Colegio E1 Consuelo y Colegio de Quebrada Grande, 
ya que el Ministerio de Educación Pública (MEP) se organizó para llevar a los estudiantes a las funciones.

Para el año siguiente, se programó otra función importante; esta vez, al aire libre, en el marco de la celebración de las Fiestas Cívicas de Liberia. La proyección se llevó a cabo el miércoles 28 de febrero del 2018, en el parque Mario Cañas Ruíz de Liberia a las 7:30 p.m., frente el atrio de la iglesia. Este sitio se abarrotó y se calcula que unas 300 personas más apreciaron el documental.

Para este fin también se creó un anuncio por Facebook: se realizó una pequeña reedición del trailer para cambiar la fecha de presentación y al inicio se le agregó un texto de "Más de 3000 liberianos ya lo vieron, pero Liberia lo volvió a pedir".

El anuncio se publicó durante quince días, del 13 al 28 de febrero, y se invirtió la suma de 30 mil colones. Tuvo un total de 59616 impresiones. Este anuncio también arrojó algunos datos interesantes como que, al igual que en el anterior, la mayoría de personas que lo observaron fueron mujeres.

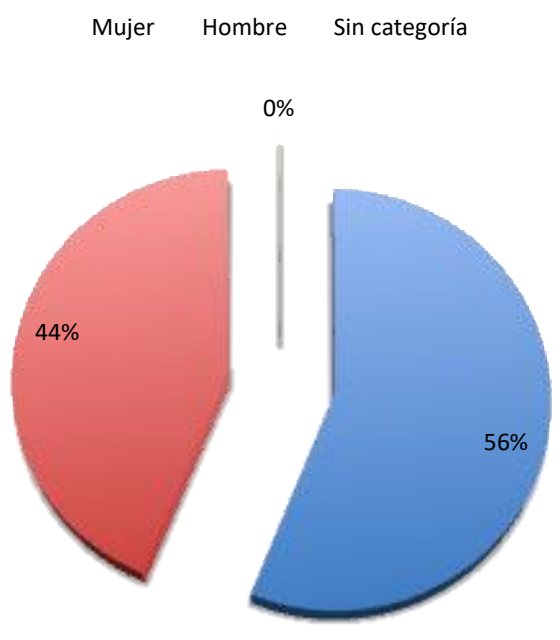

Figura 8 Alcance por sexo de promoción en Facebook del 13 al 18 de febrero del 2018 de «Una Fiesta en Liberia» para presentación en el parque Mario Cañas Ruiz. Fuente: Facebook de Audiovisuales UNED, 2019.

En dicha proyección estuvo presente el Consejo Universitario de la UNED, que (en posterior sesión) declaró el documental como de interés institucional.

Antes de colocar el audiovisual disponible para canales de televisión y en el sitio de YouTube de Audiovisuales UNED; también se llevó a cabo una promoción en exhibiciones de cine fuera del país. Se inscribió, adicionalmente, en algunos festivales de cine y premiaciones internacionales.

En setiembre del 2018, la filmación «Una Fiesta en Liberia» fue galardonada con el premio a la Mejor Película Documental Experimental (Best Music Experimental
Documentary Film) durante el Festival de Cine de la Consonancia de Música y Danza (Consonance Music \& Dance Film Festival), que produce la organización Movie Screen Pro, con sede en Los Ángeles, California.

Por otra parte, en ocasión de los premios Documentales de Impacto (Impact Docs Awards), con sede en La Jolla, California, en enero del 2019, a la producción audiovisual se le otorgó reconocimientos en siete categorías, a saber:

- Premio a la Excelencia en la categoría de Documental con 
Temática Latina/Hispana (Award of Excellence: Latin / Hispanic)

- Premio a la Excelencia en la categoría de Documental con la Mejor Investigación (Award of Excellence: Research)

- Premio a la Excelencia en la categoría de Documental Histórico/Biográfico (Award of Excellence: History / Biographical)

- Premio al Mérito en la categoría Largometraje Documental (Award of Merit: Documentary Feature)

- Premio al Mérito en la categoría de Mejor Dirección (Award of Merit: Direction)

- Premio al Mérito en la categoría de Mejor Edición (Award of Merit: Editing)

- Premio al Mérito en la categoría de Mejor Edición y Mezcla de Sonido (Award of Merit: Sound Editing / Sound Mixing) de Cine de Los Grandes Lagos (Great Lakes International Film Festival) que tuvo lugar en Pensilvania, en septiembre del 2018. También fue parte de la selección oficial en el Festival de Cine Digital en Línea Premios Griffix 2018 (Digital Griffix 2018), que se celebró en Montreal, Canadá, en diciembre del 2018.

Durante el 2019, «Una Fiesta en Liberia» se exhibió como selección oficial en el Festival Internacional de Cine de Columbus (Columbus International Film Festival), el 13 de abril. En este mismo año formó parte de la selección oficial de la tercera edición del Festival de Cine Sueños de Hollywood (Hollywood Dreams Film Festival), que se llevó acabo entre julio y agosto en Las Vegas, Nevada.

En septiembre del 2018, en Costa Rica, recibió la Mención Honorífica del Premio en Producción Audiovisual René Picado Esquivel, otorgado por el COLPER de Costa Rica.

Por el momento (2019), con estos sellos oficiales de festivales y concursos ha quedado «Una Fiesta en Liberia»:

El documental se exhibió como parte de la selección oficial del Festival Internacional

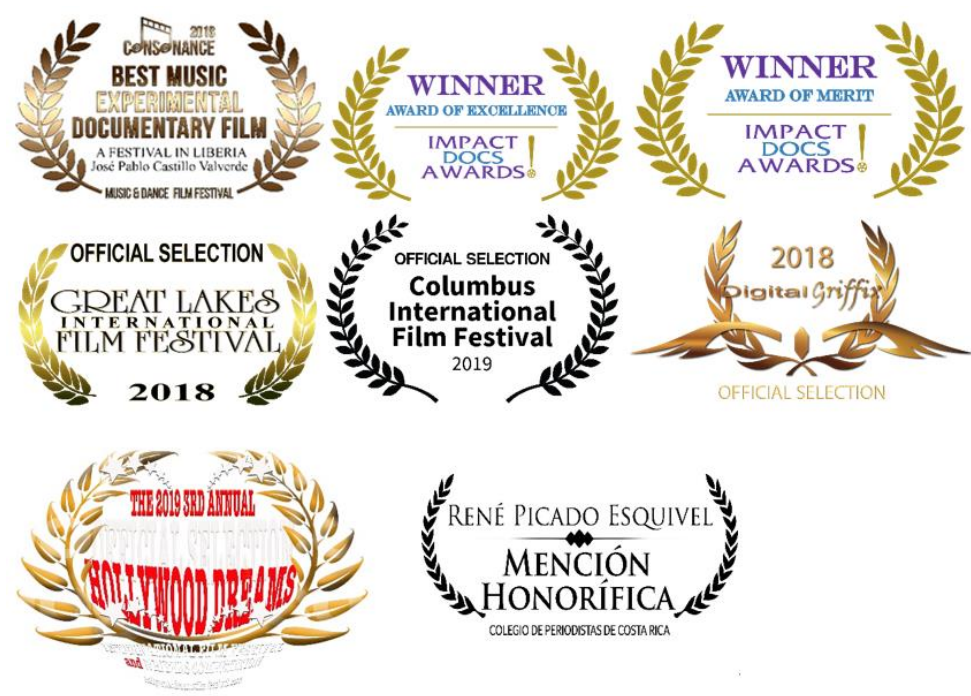

Figura 9 Laureles otorgados a «Una Fiesta en Liberia» en concursos y festivales de cine nacionales e internacionales. Fuente: Archivos de Audiovisuales UNED, 2017- 2019. 


\section{Conclusiones y reflexiones finales}

Como lo explica Petrozzi (2018), el contexto latinoamericano implica idear diversas formas de promoción de sus pueblos, que incluyan su riqueza cultural e histórica, con el fin de exportar productos o atraer inversiones. Al ser Guanacaste la cuna del folclore, de muchas tradiciones, de una diversidad enorme en cuanto a mezcla de etnias y de orígenes en sus diferentes centros de población, entonces la obra audiovisual se convierte en un medio idóneo para registrar las tradiciones. El registro de tales tradiciones contribuye al resguardo de los legados culturales para las futuras generaciones.

Siguiendo las definiciones que brinda Domínguez (2005), cuando se produce un documental, a la vez se está ejecutando una investigación en la cual se presenta una situación de la realidad, desde la perspectiva de un director. El documental es, por ende, una investigación de carácter audiovisual y que las futuras generaciones pueden usar como documento para informarse y reconstruir el pasado. Por esta razón, «Una Fiesta en Liberia» y «Las Tierras de la Princesa Nandayure» se han convertido en una representación de las realidades que experimentan diversos pueblos de la provincia de Guanacaste y cuyo registro produjo significados por medio del lenguaje audiovisual.

En su parte de producción documental, la UNED tiene un pilar en la vinculación universitaria con las comunidades y como parte de sus proyectos de extensión. De la misma manera, ha evolucionado en la distribución de su video educativo al adaptarse a los sistemas de reproducción y difusión del momento e incursionando en los últimos tiempos en la distribución y promoción por medio de las redes sociales.

Derivado de las presentaciones de los documentales en cuestión, en especial en espacios públicos y las salas de cine, se puede afirmar que los espectadores, en su contexto, observaron los significados generados por los audiovisuales con respecto a su cultura; y, asimismo, es notable cómo en todo producto documental hay una reinterpretación por parte de cada miembro del público.

El reflejo de la vida cotidiana, la historia y las representaciones culturales que aún se conservan en algunas comunidades de Guanacaste vuelven a estos sitios idóneos, ya que cuentan con un gran potencial para la documentación de la vida cotidiana y las tradiciones. Como parte de la preservación de la historia y la cultura de los pueblos, resulta primordial el uso de equipos de grabación sonora y filmación de corte profesional, toda vez que brindan más detalle y fidelidad de lo que se registra. Lo anterior permite también que la calidad del material exhibido trascienda las fronteras, perdure más en el tiempo y que sea observado en espacios extranjeros.

Según lo explica Getino (2007), "la gestión estatal en materia de promoción y fomento del sector de la comercialización es de una importancia sustancial para el desarrollo del cine y la cultura - además de la economía- nacional." (p. 194). En estos tiempos de información difundida por redes sociales, resulta crucial la inversión de fondos económicos en promoción para exhibir los trabajos audiovisuales. Dicha iniciativa debe ser parte de las estrategias de extensión social de las universidades estatales que poseen oficinas dedicadas a la producción audiovisual educativa.

La inclusión y búsqueda de espacios de exhibición en salas de cine comerciales faculta que los documentales sobre los pueblos logren más repercusión en cuanto a la cantidad de observadores. Ello es particularmente significativo entre los pobladores que habitan los sitios mismos donde se registró la historia audiovisual. En el caso particular de Liberia, presenta 
una gran ventaja respecto de la mayoría de centros de población de Guanacaste, puesto que existe una cadena regional de cines que opera en la zona y que abre sus puertas para funciones de proyección de documentales. Tales proyecciones, aunque gratuitas, se vuelven rentables para las salas de cine porque las empresas exhibidoras lucran por el consumo de bebidas y alimentos que los asistentes ingieren como parte de la práctica de ir a estos espacios de entretenimiento.

La búsqueda de exhibición de los materiales audiovisuales en concursos y galardones de cine internacionales es indispensable, puesto que coloca la película en la palestra mundial y, en este caso, se dan a conocer la historia, la cultura y el folclore de los pueblos guanacastecos a espectadores de distintas partes del orbe.

\section{Referencias}

Abaroa, G. (2018). Introducción: Premios, premios y más premios. En O. Berrendo, J. A. Serrano y E. Encinas (Eds.). Panorama Audiovisual Iberoamericano 2018. Madrid: Egeda, pp. 11-18.

Castillo, J. P. (2010). Producción del documental educativo "Fuego y Hielo en Talamanca" como apoyo a la construcción de conocimientos sobre los procesos de vulcanismo y glaciación en la Cordillera de Talamanca para la Cátedra de Geociencias y el Programa de Producción de Material Audiovisual de la Universidad Estatal a Distancia (tesis de maestría). Sistema de Estudios de Posgrado. Heredia, Costa Rica: Universidad Nacional (UNA).
Cátedra de Historia de la Universidad Estatal a Distancia (2020, 10 de junio). Festival de la Guanacastequidad. Recuperado de

https://historiauned.net/guanaca stequidad

Domínguez, G. (2005). Video documental: del Huipil a la Chilaba. Musulmanes en Chiapas. Cholula, Puebla, México (tesis profesional, licenciatura en ciencias de la comunicación). Puebla: Departamento de Ciencias de la Comunicación. Escuela de Ciencias Sociales, Universidad de las Américas de Puebla.

European Audiovisual Observatory, Council of Europe (2018). Focus 2018: World Film Market Trends. París: Global Rouge (Les DeuxPonts).

García, A. (2019, 9 julio). Las métricas social media a tener en cuenta: alcance vs. impresiones. Recuperado de https://blog.cooltabs.com/es/metricas-alcanceimpresiones/

Getino, O. (2007). Cine iberoamericano: los desafíos del nuevo siglo. Buenos Aires: Instituto Nacional de Cine y Artes Audiovisuales.

Irigaray, F. (2014). La ciudad como plataforma narrativa. En F. Irigaray y A. Lovato (Eds.). Hacia una comunicación transmedia 2014. Rosario, Argentina: UNR Editora. Editorial de la Universidad Nacional de Rosario, pp. 113-131.

Ley n. ${ }^{\circ} 6044$ de Creación de la Universidad Estatal a Distancia 
(UNED) (1977, 12 de marzo). Diario Oficial La Gaceta, n. ${ }^{\circ} 50$.

Metz, C. (2017, 12 de octubre). How Facebook's Ad System Works. The New York Times. Recuperado de https://www.nytimes.com/2017 /10/12/technology/howfacebook-ads-work.html

Miller, T. (2017). Introduction: Global Popular Culture. En T. Miller (Ed.). The Routledge Companion to Global Popular Culture 2017. New York: Routledge, Taylor \& Francis, pp. 1-10.

Petrozzi, F. (2018). La obra audiovisual como herramienta de promoción de un país. En O. Pérez, J. A. Serrano y E. Encinas (Eds.). Panorama Audiovisual Iberoamericano 2018. Madrid: Egeda, pp. 143-146.

Quartesan, A., Romis, M. y Lanzafame, F. (2007). Cultural Industries in Latin America and the Caribbean: Challenges and
Opportunities. Recuperado de https://pdfs.semanticscholar.org/ 53c5/7ff2ca2a9d03f5725ee9d435f 0511622c58f.pdf

Ramírez, J. (1950). La venganza de Nandayure. La Nación. San José: La Nación.

Román, R. y Castillo, J. P. (2010). La calidad: el desafío de la televisión. San José: EUNED.

Vargas, V. B. (2003). Nandayure: su historia, su folclore, su gente. Heredia, Costa Rica: Programa de Impresiones y Publicaciones UNA.

Recibido: 05 de noviembre de 2019 Aceptado: 20 de mayo de 2020 